\title{
Avaliação das condições de trabalho de agentes de bagagem e operadores de rampa de um Aeroporto Brasileiro
}

\author{
RESUMO
}

\section{José Wendel dos Santos} wendel@email.com

Universidade Federal de Sergipe (UFS), São Cristóvão, Sergipe, Brasil

Luciano Fernandes Monteiro lucianofm2007@gmail.com Universidade Federal de Sergipe (UFS), São Cristóvão, Sergipe, Brasil
O objetivo deste estudo foi avaliar as condições de trabalho dos agentes de bagagem e operadores de rampa de um aeroporto brasileiro para identificar os fatores de riscos associados às atividades desenvolvidas por esses trabalhadores e propor soluções ergonômicas passíveis de serem realizadas pela empresa. Para este fim, foram realizadas as seguintes medições: da antropometria dos trabalhadores; do aparato instrumental utilizado na atividade de trabalho; da biomecânica utilizada durante a realização das tarefas; e das variáveis ambientais dos postos de trabalho. A avaliação das condições biomecânicas de trabalho foi realizada com o uso do Programa Tridimensional de Predição de Postura e de Força Estática (3DSSPP) e da Equação de Levantamento Revisada (ELR) do National Institute for Occupational Safety and Health (NIOSH). A avaliação das condições ambientais de trabalho foi realizada por meio da comparação entre os limites de tolerância estabelecidos pela legislação brasileira e os níveis mensurados nos postos de trabalho. Em relação às condições biomecânicas de trabalho, ficou evidente que a movimentação manual das bagagens e mercadorias com peso acima do recomendado provocou compressões potencialmente danosas à coluna lombar, principalmente dos operadores de rampa. Quanto às condições ambientais de trabalho, os resultados demonstraram que algumas variáveis ambientais estavam fora dos limites de tolerância, em especial a temperatura, iluminação e ruído. De maneira geral, espera-se que os fatores de riscos identificados neste estudo sensibilizem os gestores de forma que as proposições ergonômicas sejam realizadas sistematicamente.

PALAVRAS-CHAVE: Condições de trabalho. Agente de bagagem. Operador de rampa. Aeroporto. 


\section{INTRODUÇÃO}

Segundo a Confederação Nacional do Transporte (2015), desde a sua criação, o transporte aéreo evoluiu em ritmo acelerado, reduzindo o tempo de deslocamento e estimulando o desenvolvimento econômico das regiões integradas à sua rede de atuação. Suas características intrínsecas de velocidade, segurança e autonomia para percorrer espaços contribuíram para a disseminação do seu uso para a movimentação de mercadorias e passageiros. No Brasil, o crescimento da economia ocorrido nos últimos anos foi uma das principais forças impulsoras para a popularização desse tipo de modal na matriz de transportes brasileira, o que se traduziu em aumento expressivo e sustentado da sua demanda.

De acordo com a Agência Nacional de Aviação Civil (2016), a demanda doméstica do transporte aéreo de passageiros mais do que duplicou nos últimos dez anos, quando obteve alta de $133 \%$ entre os anos de 2006 e 2015 e crescimento médio de 9,8\% ao ano. Dessa maneira, conforme ponderam Zimmermann \& Oliveira (2012), para atender a essa crescente demanda as companhias aéreas intensificaram o uso de sua frota no âmbito de suas redes de operação e ampliaram sua capacidade produtiva instalada, em termos de número e tamanho de aeronaves e de frequências de voo. Assim, em 2015, foram realizados 1,08 milhões de voos e a movimentação de 117,8 milhões de passageiros e 1,11 milhões de mercadorias por empresas brasileiras, considerando o total das operações domésticas e internacionais (ANAC, 2016).

Não por acaso, as companhias aéreas tiveram que minimizar ao máximo o tempo de processamento das bagagens e mercadorias, sobretudo, nas conexões entre voos, o que ocasionou a intensificação da carga de trabalho dos profissionais que prestam os serviços de assistência em terra nos aeroportos. No entanto, apesar da aparente modernização da infraestrutura aeroportuária brasileira observa-se que grande parte do contingente de trabalhadores envolvidos nesse processo desenvolvem atividades ainda rudimentares, com grau mínimo de tecnologia, como é o caso dos agentes de bagagem e operadores de rampa.

Esses profissionais fazem parte do quadro de funcionários das próprias companhias aéreas ou de empresas terceirizadas prestadoras de serviços auxiliares de transporte aéreo, e são responsáveis pelo manuseio das bagagens e mercadorias, atuando nos terminais de partida, chegada e de transferência do aeroporto. $\mathrm{O}$ trabalho realizado pelos agentes de bagagem e operadores de rampa é caracterizado por uma atividade que tem alta demanda de energia e por requerer medidas de força física durante a elevação e movimentação das bagagens e cargas de diferentes pesos, formas e tamanhos. Para além destes fatores, por desenvolverem suas atribuições, na maior parte do tempo, no ambiente externo ao aeroporto, estão sujeitos, também, às intempéries do tempo e ao ruído ocupacional.

A partir dessa preocupação, diversas pesquisas internacionais têm sido operacionalizadas para avaliar as condições de trabalho desses profissionais. Yoopat et al. (2002) conduziram uma pesquisa para investigar os efeitos combinados da carga de trabalho físico e estresse térmico sobre os agentes de bagagem e operadores de rampa do Aeroporto de Bangkok, na Tailândia. Dos parâmetros analisados, observaram que a exposição à radiação solar associada à carga de trabalho contribuiu para o aumento da temperatura corporal dos 
trabalhadores durante a execução da tarefa, e por essa razão, concluíram que medidas de combate a esta exposição devem ser adotadas.

Gugliermett et al. (2010) avaliaram a exposição dos operadores de rampa ao ruído ocupacional durante o desenvolvimento das atividades laborais próximas as aeronaves no Aeroporto Internacional de Roma, na Itália. Nesta análise, observaram que os trabalhadores estavam expostos a níveis de ruído ocupacional superior a $87 \mathrm{~dB}(\mathrm{~A})$, e que a situação de trabalho demandava a implantação de medidas preventivas para reduzir os riscos de desenvolvimento de doenças auditivas.

Oxley, Riley e Tapley (2009) buscaram identificar a prevalência de manifestações sintomáticas corporais entre agentes de bagagem e operadores de rampa do Aeroporto de Midlands, no Reino Unido. No caso apresentado, os resultados apontaram que a maioria dos trabalhadores relatou ter dor na coluna lombar, nos joelhos, pescoço e no ombro, além de atribuir os sintomas ao trabalho realizado.

Tafazzol et al. (2015), ao analisarem os aspectos epidemiológicos e biomecânicos da logística de preparação e distribuição de bagagem e mercadorias do Aeroporto Internacional de Mehrabad, no Irã, não somente constataram alta prevalência de dor na região lombar, joelhos e pescoço, como também identificaram que a movimentação manual das bagagens e mercadorias com peso acima do limite recomendado ocasionava forças de compressão potencialmente danosas à coluna vertebral dos trabalhadores, predispondo-os ao acometimento de lombalgia.

Verifica-se, porém, que os estudos realizados no contexto brasileiro ainda são escassos. Portanto, com o intuito de contribuir para o tratamento desta problemática o presente estudo teve como objetivo avaliar as condições de trabalho dos agentes de bagagem e operadores de rampa de um aeroporto brasileiro, para identificar os fatores de riscos associados às atividades desenvolvidas por esses trabalhadores e propor soluções ergonômicas passíveis de serem realizadas pela empresa analisada.

\section{METODOLOGIA}

Este estudo transversal foi conduzido com agentes de bagagem e operadores de rampa que atuam na logística de preparação e distribuição de bagagens e mercadorias do Aeroporto de Aracaju/SE, localizado na zona sul da capital sergipana, o qual foi fundado e incorporado à Empresa Brasileira de Infraestrutura Aeroportuária (INFRAERO/SE) no ano de 1975. O sítio aeroportuário abrange uma área total de 3.874 milhões de $\mathrm{m}^{2}$, um pátio de aeronaves com $22.356 \mathrm{~m}^{2}$, uma única pista de pouso e decolagem com $2.200 \mathrm{~m}$ e um terminal de passageiros com $9.321 \mathrm{~m}^{2}$. Esse complexo aeroportuário possui aproximadamente 1.003 colaboradores para atender a demanda anual de 2,6 milhões de passageiros e 20 voos regulares diários realizados pelas quatro maiores companhias aéreas do país. 


\section{PROCEDIMENTOS DE COLETA DE DADOS}

A coleta de dados ocorreu durante a primeira quinzena de dezembro de 2015, das $08 \mathrm{~h} 00 \mathrm{~min}$ às $17 \mathrm{~h} 00 \mathrm{~min}$, e foi sistematizada em três etapas distintas. $\mathrm{Na}$ primeira etapa foi conduzida uma entrevista pré-agendada com os representantes da empresa responsável pelos serviços de serviços de assistência em terra, das companhias aéreas e da INFRAERO/SE. Nesta etapa, foi possível conhecer as instalações físicas do aeroporto, a logística de preparação e distribuição de bagagens e mercadorias, selecionar os voluntários para compor o Grupo Homogêneo de Exposição (GHE) e definir a agenda de pesquisa de campo.

$\mathrm{Na}$ segunda etapa foram coletados os dados antropométricos dos trabalhadores e do aparato instrumental utilizado no processamento das bagagens e mercadorias, com o auxílio do antropômetro vertical portátil, balança plataforma portátil e fita antropométrica. Além disso, foi realizada a observação sistêmica da biomecânica utilizada pelos trabalhadores durante a execução das tarefas. Esses dados foram documentados e registrados por meio de fotos e filmagens.

Na terceira etapa foram coletados os dados ambientais na aérea operacional do aeródromo. As variáveis referentes à temperatura, umidade relativa e iluminância foram coletadas em cinco pontos preestabelecidos, próximos aos trabalhadores durante a execução das atividades laborais utilizando o equipamento denominado Termo-higro-decibel-luxímetro (THDL/400), que integra funções de termômetro, higrômetro, decibelímetro e luxímetro. Os intervalos entre as medições obedeceram à demanda dos serviços dos trabalhadores. Para cada ciclo de trabalho foram tomadas no mínimo duas medidas, enquanto o monitoramento global dessas variáveis foi de 58,61 \pm 2 horas.

O Termômetro de Globo Portátil (ITWTG/2000) foi utilizado para medir as temperaturas de bulbo seco, úmido e de globo nos postos de trabalho. O monitoramento global desse índice foi de $42,45 \pm 3$ horas. Conforme as especificações da Norma de Higiene Ocupacional NHO 06 (2002), foi utilizada a Equação (1) para calcular o Índice de Bulbo Úmido Termômetro de Globo (IBUTG) no posto de trabalho sem carga solar, isto é, ambiente onde os agentes de bagagem desempenhavam suas atribuições, e a Equação (2) para calcular o IBUTG no posto de trabalho dos operadores de rampa, que possuía carga solar.

$$
\begin{array}{r}
\text { IBUTG }=0,7 \mathrm{Tbn}+0,3 \mathrm{Tg} \\
\text { IBUTG }=0,7 \mathrm{Tbn}+0,2 \mathrm{Tg}+0,1 \mathrm{Tbs}
\end{array}
$$

Em que: Tbn é a temperatura de bulbo úmido natural; Tg é a temperatura de globo; Tbs é a temperatura de bulbo seco (temperatura do ar).

Os níveis de ruído ocupacional durante a jornada de trabalho foram tomados por meio de dois dosímetros de ruído (DOS-600), que possuíam escala de medição de ruído de 70 a $140 \mathrm{~dB}$ e precisão de $\pm 1,5 \mathrm{~dB}$. Conforme as especificações da NHO 01 (1999), os equipamentos foram ajustados para operarem no circuito de compensação (A), com resposta lenta e critério de referência de $85 \mathrm{~dB}$, que corresponde a dose de $100 \%$ para uma exposição de 8 horas de trabalho. 0 monitoramento global do nível de pressão sonora foi de $61,78 \pm 5$ horas. 


\section{PROCEDIMENTOS DE ANÁLISE DOS DADOS}

Em relação às variáveis ambientais, inicialmente foi realizada a análise estatística do conjunto de dados para obter as medidas de tendência central e medidas de variabilidade, sendo posteriormente analisadas a partir da comparação dos níveis obtidos na pesquisa de campo com os níveis estabelecidos na legislação brasileira, especificamente nas Normas Regulamentadoras (NR) do Ministério do Trabalho e Emprego (MTE).

Quanto à análise biomecânica dos trabalhadores, foi utilizada a base de dados com registros de doze ciclos de trabalho dos agentes de bagagem e dez ciclos de trabalho dos operadores de rampa, que associada aos dados antropométricos e do aparato instrumental foram submetidos à análise do Programa Tridimensional de Predição de Postura e de Força Estática (3DSSPP), desenvolvido pelo Centro de Ergonomia da Universidade de Michigan, para analisar as solicitações biomecânicas e mensurar a sobrecarga física na coluna lombar dos trabalhadores durante a execução das atividades.

Complementarmente, utilizou-se a Equação de Levantamento Revisada (ELR), proposta pelo National Institute for Occupational Safety and Health (NIOSH), para determinar o Limite de Peso Recomendado (LPR) e o Índice de Levantamento (IL), de maneira que uma considerável porcentagem da população dos trabalhadores possa realizar as tarefas ao longo de um turno de 8 horas, sem aumentar o risco de lombalgia. O LRP foi obtido através da Equação 3.

$$
\text { LPR }=23 \times \text { FDH } \times \text { FAV } x \text { FDVP } x \text { FFL } x \text { FRLT } x \text { FQPC }
$$

Em que: o valor 23 corresponde ao peso limite ideal, isto é, aquele que pode ser manuseado sem expor o trabalhador a riscos de lombalgia; FDH é o fator distância horizontal da pega ao ponto médio entre os tornozelos, dado por $(25 / \mathrm{H})$; FAV é o fator altura vertical das mãos em relação ao solo no início da elevação, dado por $(1-(0.0038 \times[V-75]))$, para alturas até acima de $75 \mathrm{~cm}$ e $(1-(-0,003$ $x$ [V - 75])), para alturas até $75 \mathrm{~cm})$; FDVP é o fator distância vertical percorrida desde a origem até o destino, dado por $(0.82+(4.5 / D)$; FFL é o fator frequência de levantamento; FRLT é o fator rotação lateral do corpo, dado por $(1-(0.0032 \times A)$; FQPC é o fator qualidade da pega da carga.

A partir do LPR, foi calculado o IL, dado pela divisão da carga real levantada pelo LPR. De acordo com Teixeira (2004), o LPR e o IL são baseados no conceito de que o risco de lombalgia relacionada ao trabalho aumenta à medida que a demanda da tarefa de levantamento aumenta. Assim, quando o valor do IL encontra-se no intervalo de 0 a 1, são necessárias mudanças ergonômicas para diminuir a demanda física geral da tarefa. Os valores entre 1,1 e 2,9 sugerem que provavelmente o trabalhador tem grandes chances de desenvolver lombalgia. Nos casos em que o valor seja igual ou superior a 3,0, aumenta-se a probabilidade de lesões irreversíveis na coluna vertebral do trabalhador (TEIXEIRA, 2004; WATERS, 1993). 


\section{RESULTADOS E DISCUSSÃO}

\section{AVALIAÇÃO DAS CONDIÇÕES ORGANIZACIONAIS E TÉCNICAS DE TRABALHO}

O ponto de indução do processamento da bagagem despachada no Aeroporto de Aracaju ocorre nos balcões ou guichês das companhias aéreas. Nesse ponto, são inseridas etiquetas de identificação nas bagagens, que posteriormente são depositadas em esteiras na qual em determinado ponto fazem com que as bagagens, inclusive de outras companhias aéreas, sejam aglomeradas e direcionadas para o sistema de verificação de segurança. Em seguida, as bagagens são encaminhadas para um túnel de classificação e a partir de um sistema computadorizado de leitura de etiquetas integrado ao processo, as bagagens são encaminhadas para a zona de preparação referente ao voo para qual foram destinadas. Esta zona está localizada no pátio do aeródromo, na qual uma empresa terceirizada atua como prestadora dos serviços de assistência em terra às companhias aéreas e à INFRAERO.

Dentre os serviços oferecidos pela empresa terceirizada, encontra-se o de logística de preparação e distribuição das bagagens, operacionalizada pelos agentes de bagagem e operadores de rampa. Todos os trabalhadores são do sexo masculino e desenvolvem suas atividades laborais em escalas pré-estabelecidas com jornada de 6 horas de trabalho diária e 1 hora de intervalo. As demais características demográficas e profissionais dos trabalhadores estão organizadas na Tabela 1.

Tabela 1 - Características demográficas e profissionais dos trabalhadores

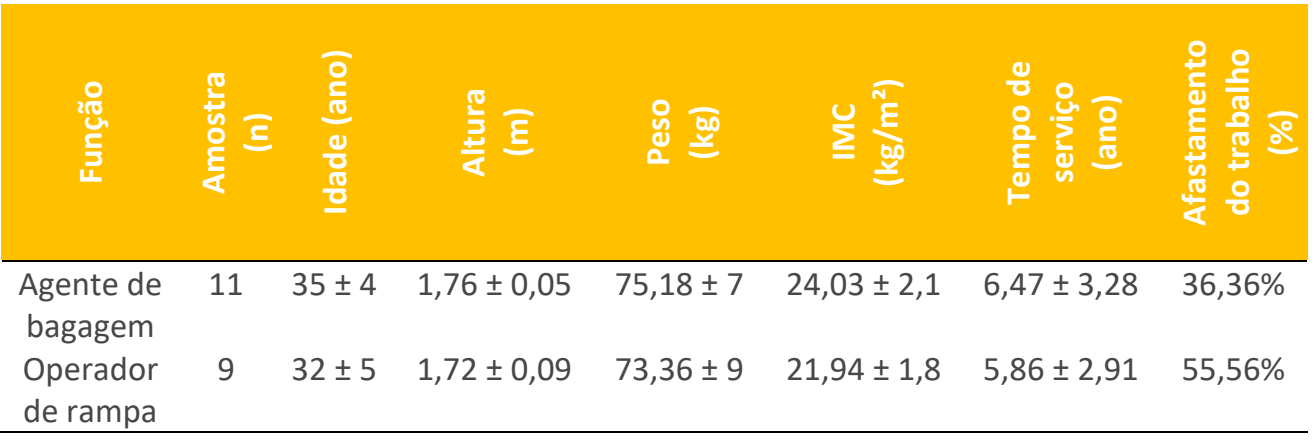

Fonte: Autoria própria (2015).

Os agentes de bagagem são responsáveis por realizar o segregamento dos volumes na área de triagem do aeroporto, por meio da leitura de etiquetas de identificação de bagagens despachadas pelas companhias. Nesse processo, os agentes de bagagem transferem as bagagens depositadas na esteira rolante com $26 \mathrm{~cm}$ de altura em relação ao solo para os carros de apoio, os quais possuem 120 $\mathrm{cm}$ de comprimento, $60 \mathrm{~cm}$ de largura, $53 \mathrm{~cm}$ de altura e capacidade de carga de $2000 \mathrm{~kg}$. O peso médio das bagagens e mercadorias processadas durante a pesquisa de campo foi de $28 \pm 6 \mathrm{~kg}(274,6 \pm 58,8 \mathrm{~N})$, com peso mínimo de $12 \mathrm{~kg}$ $(117,68 \mathrm{~N})$ e o máximo de $34 \mathrm{~kg}(333,43 \mathrm{~N})$. Esse processo teve tempo de duração médio de $14 \pm 5$ minutos. Na Figura 1 observa-se a operação de transferências de bagagens despachadas para o carro de apoio. 
Figura 1 - Operação de transferência de bagagens para o carro

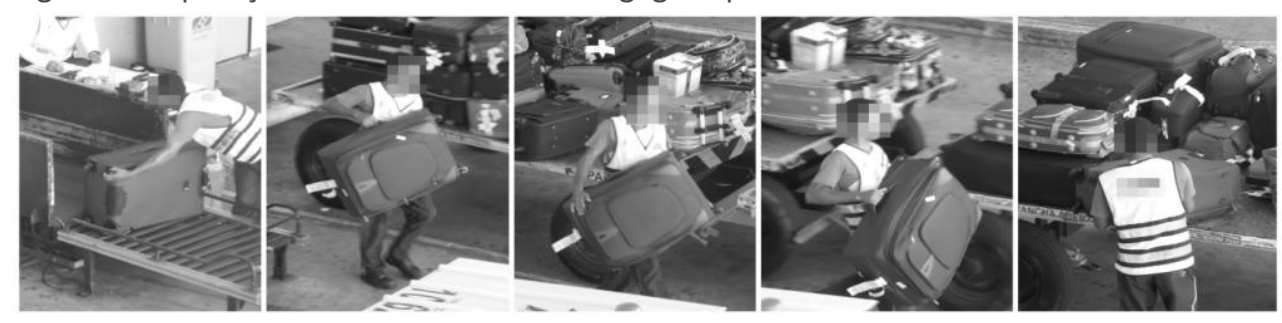

Fonte: Pesquisa de campo (2015).

Em seguida, os agentes de bagagem acionam os tratoristas de reboque para o acoplamento dos carros de apoio nos minitratores, que são encaminhados para a área de carregamento junto às aeronaves. No caso de mercadorias, depois dos trâmites burocráticos realizados no setor adjacente ao saguão de embarque, estas são encaminhadas para a área de carregamento ou para o setor de armazenamento de cargas. $O$ processo de transferência dessas mercadorias para o carro de apoio é semelhante ao realizado no setor de triagem de bagagens despachadas.

Os operadores de rampa são responsáveis pelo carregamento, descarregamento e segregamento dos volumes nas aeronaves. Nesse processo, após o tratorista de reboque posicionar o carro de apoio próximo ao compartimento da aeronave, os operadores de rampa sobem na base do carro de apoio e de forma coordenada, retiram e depositam as bagagens e mercadorias do compartimento da aeronave para a base do carro de apoio, que distava $64 \mathrm{~cm}$ da posição inicial do operador. O processo teve a duração média de $13 \pm 4$ minutos. $\mathrm{Na}$ Figura 2 observa-se a operação de descarregamento de mercadorias do compartimento das aeronaves.

Figura 2 - Processo de descarregamento de bagagens na aeronave
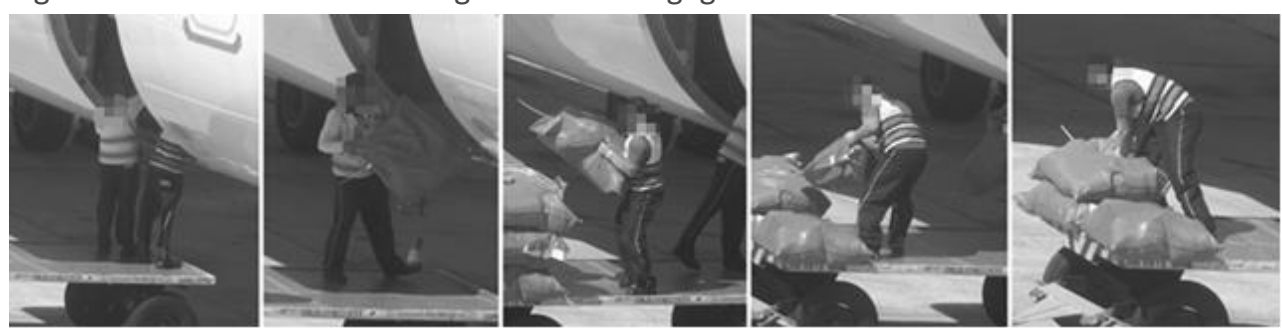

Fonte: Pesquisa de campo (2015).

Após a aeronave ser totalmente descarregada, os tratoristas de reboque transportam as bagagens ou mercadorias para o setor de triagem, onde são realizados os procedimentos burocráticos pela Polícia Federal e Receita Federal e liberadas não havendo nenhuma irregularidade.

Concomitantemente, ocorre a operação de carregamento das bagagens despachadas ou mercadorias nas aeronaves para voos das demais companhias aéreas. Esse processo é semelhante ao realizado no descarregamento, porém no fluxo inverso e tem duração média de $16 \pm 3$ minutos. 


\section{AVALIAÇÃO DAS CONDIÇÕES BIOMECÂNICAS DE TRABALHO}

Em relação às atividades desenvolvidas pelos agentes de bagagem, foi possível perceber que em todos os casos, os agentes flexionaram o tronco à frente da bagagem perfazendo um ângulo de $33,78^{\circ} \pm 2,6^{\circ}$ graus, tencionando os músculos do pescoço e coluna vertebral. Geralmente, os dois braços permaneceram estendidos e, logo em seguida, os agentes flexionaram o cotovelo direito e os dois joelhos para pegar a bagagem depositada na esteira rolante. Com o uso de manejo grosseiro, os agentes retornaram a posição anterior, por meio da extensão do tronco e giraram o corpo em um ângulo de $93,18^{\circ} \pm 4,1^{\circ}$ graus. Esse movimento de tronco associado ao levantamento da bagagem ocasionou a compressão média nos discos L4/L5 e L5/S1 da coluna vertebral dos agentes na ordem de $3394 \pm 385$, 1 N.

Logo após levantar a bagagem, $86.36 \%$ dos agentes flexionou as pernas, variou o movimento dos braços entre flexão e extensão, e durante o trajeto posicionaram a mão esquerda na base da bagagem ou mercadoria. No momento em que os agentes se posicionaram em frente ao carro de apoio, giram novamente o corpo em um ângulo de $88,4^{\circ} \pm 5,3^{\circ}$ graus, suas pernas ficaram estendidas e seus braços flexionados no momento em que depositavam a bagagem ou mercadoria sobre o carro de apoio. Durante esse trajeto de deslocamento da bagagem para o carro de apoio, a compressão média nos discos L4/L5 e L5/S1 dos agentes foi calculada em $2893 \pm 267,7 \mathrm{~N}$, que diferentemente da primeira posição, foi atenuada pelo fato de que a maioria dos agentes aproximava a bagagem ao corpo. A Figura 3 demonstra esta dinâmica.

Figura 3 - Principais solicitações biomecânicas durante a preparação das bagagens despachadas

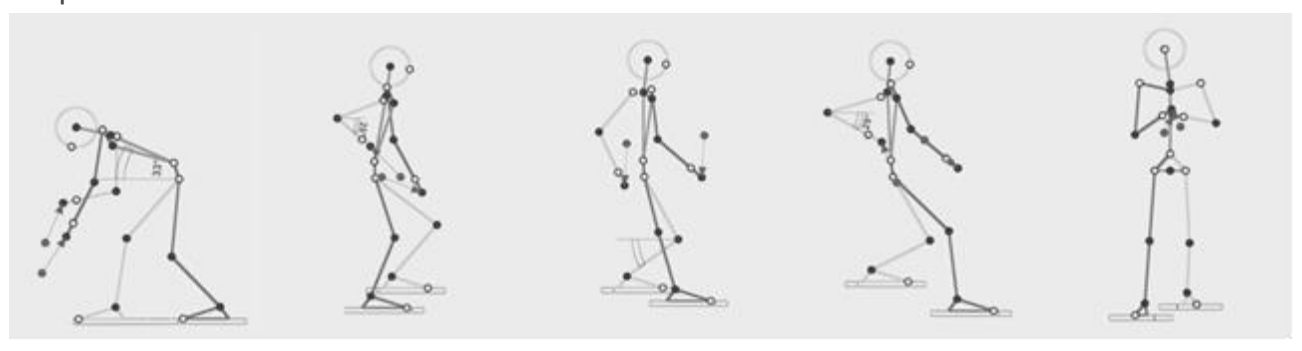

Fonte: Autoria própria (2016).

No que se refere aos operadores de rampa, durante o processo de carregamento e descarregamento de das aeronaves, observou-se que para agarrar a bagagem ou mercadoria situada na entrada do compartimento da aeronave a biomecânica comum entre os operadores se deu nos seguintes movimentos: extensão dos dois braços acima do nível do ombro, flexão do tronco para frente, e variações de flexão e extensão das pernas. Após agarrá-las, os operadores de rampa flexionaram os braços e giraram o corpo perfazendo um ângulo médio de $127,9^{\circ} \pm 5,1^{\circ}$ graus para depositá-las na base do carro de apoio. Nesse momento, foram observadas flexões de tronco com variação de ângulo entre $21,14^{\circ} \pm 4,78^{\circ}$ a $53,67^{\circ} \pm 2,32^{\circ}$ graus, devido ao empilhamento das bagagens ou mercadorias umas sobre as outras. Durante as flexões, a compressão média nos discos L4/L5 e L5/S1 
dos operadores foi de $3395,31 \pm 253,67 \mathrm{~N}$. Na Figura 4 é possível visualizar as principais solicitações biomecânicas durante essa operação.

Figura 4 - Principais solicitações biomecânicas durante a operação de descarregamento de cargas da aeronave

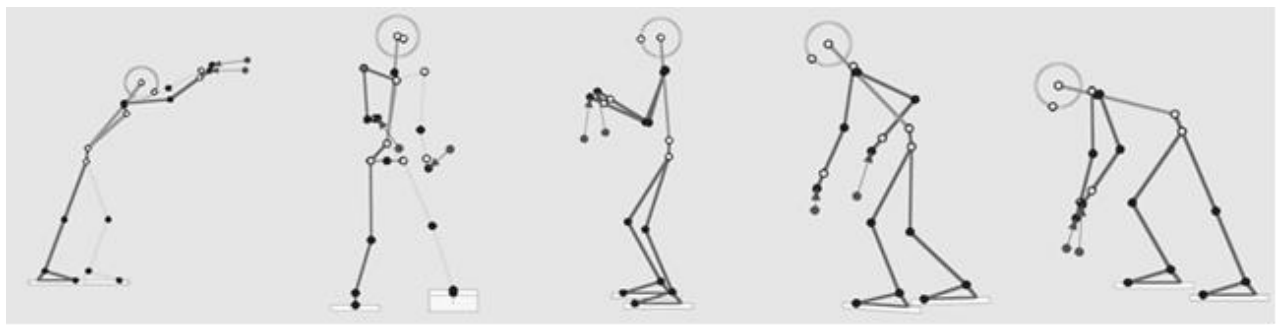

Fonte: Autoria própria (2016).

Nessa avaliação, os achados possibilitaram considerar que a biomecânica utilizada pela maioria dos trabalhadores compromete a estrutura da coluna vertebral, em especial a região lombar. Segundo Merino (1996), as compressões multidirecionais nos discos L4/L5 e L5/S1 da coluna vertebral não deve ser superior a $3400 \mathrm{~N}$, pois quando são submetidos a compreensões acima desta ordem provoca micro traumas, que dependendo do grau de evolução, resultam em lombalgia. Muito embora a lombalgia não se caracterize como uma doença e sim como um sintoma de quadro álgico intenso, essa patologia é causa frequente de morbidade e incapacidade ao trabalho.

Brasil (2003) afirma que os sintomas da lombalgia tendem a ser potencializado, geralmente, nos finais de jornada de trabalho ou durante os picos de produção. No entanto, a necessidade de responder às exigências do trabalho, a falta de informação e outras contingências estimula o trabalhador a suportar os sintomas e a continuar trabalhando. Nesse sentido, Byrns (2002) salienta que as recorrências de episódios de lombalgia aguda evoluem para casos crônicos, e nestes casos, menor será a chance de o trabalhador retornar com as mesmas condições físicas.

Desse modo, observa-se que entre as causas de lombalgia evidencia-se como fator principal as atividades de levantamento manual de cargas. Nesse sentido, ao levantar, puxar, ou empurrar a bagagem ou mercadoria é fundamental que o trabalhador considere o peso e a posição da mesma em relação ao eixo do seu corpo, pois estes fatores estão estreitamente relacionados às forças de compressão geradas na coluna lombar e o acometimento de lombalgia.

Para as atividades analisadas, a ELR sugeriu a redução drástica do peso manipulado pelos agentes de bagagem de $28 \mathrm{~kg}$ para 9,20 kg e para os operadores de rampa de $28 \mathrm{~kg}$ para 7,75 kg. Dentre as variáveis da localização-padrão de levantamento analisadas, a variável FRLT, que corresponde ao esforço para a rotação do corpo associada ao levantamento de bagagem ou mercadoria, foi a que mais contribuiu para valores inadequados do LPR e IL para ambas as atividades. Na Tabela 2 é possível visualizar aos coeficientes das variáveis da localização-padrão de levantamento e dos valores de LPR e IL. 
Tabela 2 - Variável da localização-padrão de levantamento

\begin{tabular}{lcccccccccc} 
Função & $23 \mathrm{~kg}$ & FDH & FAV & FDVP & FFL & FRLT & FQPC & LPR & IL \\
\hline $\begin{array}{l}\text { Agente de } \\
\text { bagagem }\end{array}$ & $23 \mathrm{~kg}$ & 1,00 & 0,81 & 0,98 & 0,80 & 0,70 & 0,90 & $\begin{array}{c}\mathbf{9 , 2 0} \\
\mathrm{kg}\end{array}$ & $\mathbf{3 , 0 4}$ \\
$\begin{array}{l}\text { Operador } \\
\text { de rampa }\end{array}$ & $23 \mathrm{~kg}$ & 1,00 & 0,86 & 0,89 & 0,80 & 0,42 & 0,90 & $\begin{array}{c}\mathbf{7 , 7 5} \\
\mathrm{kg}\end{array}$ & $\mathbf{3 , 6 1}$ \\
\hline
\end{tabular}

Fonte: Autoria própria (2016).

\section{AVALIAÇÃO DAS CONDIÇÕES AMBIENTAIS DE TRABALHO}

Os dados coletados nos postos de trabalho foram tratados estatisticamente e organizados na Tabela 3. Dessa maneira, pode-se fazer uma comparação simplificada entre os limites de tolerância preconizados pela legislação brasileira (condição ideal) e a realidade do ambiente analisado.

Tabela 3 - Variáveis ambientais

\begin{tabular}{|c|c|c|c|c|c|}
\hline $\begin{array}{c}\text { Variáveis } \\
\text { ambientais }\end{array}$ & $\begin{array}{l}\text { Agentes de } \\
\text { bagagem }\end{array}$ & $\begin{array}{l}\text { Operadores } \\
\text { de rampa }\end{array}$ & $\begin{array}{l}\text { Limite de } \\
\text { tolerância }\end{array}$ & $\begin{array}{l}\text { Legislação } \\
\text { pertinente }\end{array}$ & $\begin{array}{l}\text { Diagnóstico } \\
\text { preliminar }\end{array}$ \\
\hline $\begin{array}{c}\text { Umidade relativa } \\
\text { média (\%) }\end{array}$ & $61,16 \%$ & $58,69 \%$ & 40 a $80 \%$ & NR-17 & Atende \\
\hline $\begin{array}{l}\text { Temperatura } \\
\text { média }(\stackrel{\circ}{ } \mathrm{C})\end{array}$ & $28,98 \stackrel{\circ}{C}$ & $29,14^{\circ} \mathrm{C}$ & 23 a $26 \stackrel{\circ}{ }=$ & NR-17 & Não atende \\
\hline IBUTG Médio (ํㅡ) & $28,23 \stackrel{\circ}{C}$ & $29,78^{\circ} \mathrm{C}$ & $27,5^{\circ} \mathrm{C}$ & NR-15 & Não atende \\
\hline $\begin{array}{l}\text { Ruído médio } \\
\qquad(\mathrm{dB} / \mathrm{A})\end{array}$ & $89,52 \mathrm{~dB}(\mathrm{~A})$ & $93,63 \mathrm{~dB}(\mathrm{~A})$ & $87 \mathrm{~dB}(\mathrm{~A})$ & NR-15 & Não atende \\
\hline $\begin{array}{l}\text { Iluminância média } \\
\qquad(\mathrm{Ix})\end{array}$ & $641,63 \mathrm{~lx}$ & $938,78 \mathrm{~lx}$ & 100 a $300 \mathrm{~lx}$ & NBR 5413 & Não atende \\
\hline
\end{tabular}

Fonte: Autoria própria (2016).

À vista do exposto na Tabela 3, observa-se que apenas a umidade relativa média presente em ambos os postos de trabalho apresentaram níveis dentro dos limites recomendados pela NR 17. A umidade relativa média no ambiente de trabalho dos agentes de bagagem foi de $61,16 \%$ e dos operadores de rampa foi de $58,69 \%$. No que se refere à temperatura, embora as atividades desenvolvidas pelos trabalhadores sejam realizadas no ambiente externo, com boa circulação natural do ar, a temperatura média em ambos os postos estava acima dos limites de exposição, que segundo a NR 17, a faixa de temperatura aceitável está entre 23 e $26^{\circ} \mathrm{C}$. A temperatura média do ambiente de trabalho dos agentes de bagagem foi de $28,98^{\circ} \mathrm{C}$ e dos operadores de rampa $29,14^{\circ} \mathrm{C}$.

O IBUTG médio calculado para os agentes de bagagem foi de $28,23{ }^{\circ} \mathrm{C}$ e dos operadores de rampa foi de $29,78{ }^{\circ} \mathrm{C}$, ambos superiores ao limite de tolerância estipulado pela NR 15. No entanto, a intermitência do trabalho por conta do regime de escalas e do tempo entre voos afasta o direito à insalubridade. No caso específico dos operadores de rampa, observa-se a influência direta da radiação solar no transcorrer da jornada de trabalho. A situação de sobrecarga térmica média se manteve praticamente durante toda a jornada de trabalho, sendo a 
maior sobrecarga térmica média observada às $12 \mathrm{~h} 00 \mathrm{~min}$, quando o IBUTG médio atingiu $32,91^{\circ} \mathrm{C}$, conforme ilustrado na Figura 5.

Figura 5 - Comportamento do IBUTG médio durante a jornada de trabalho dos operadores de rampa

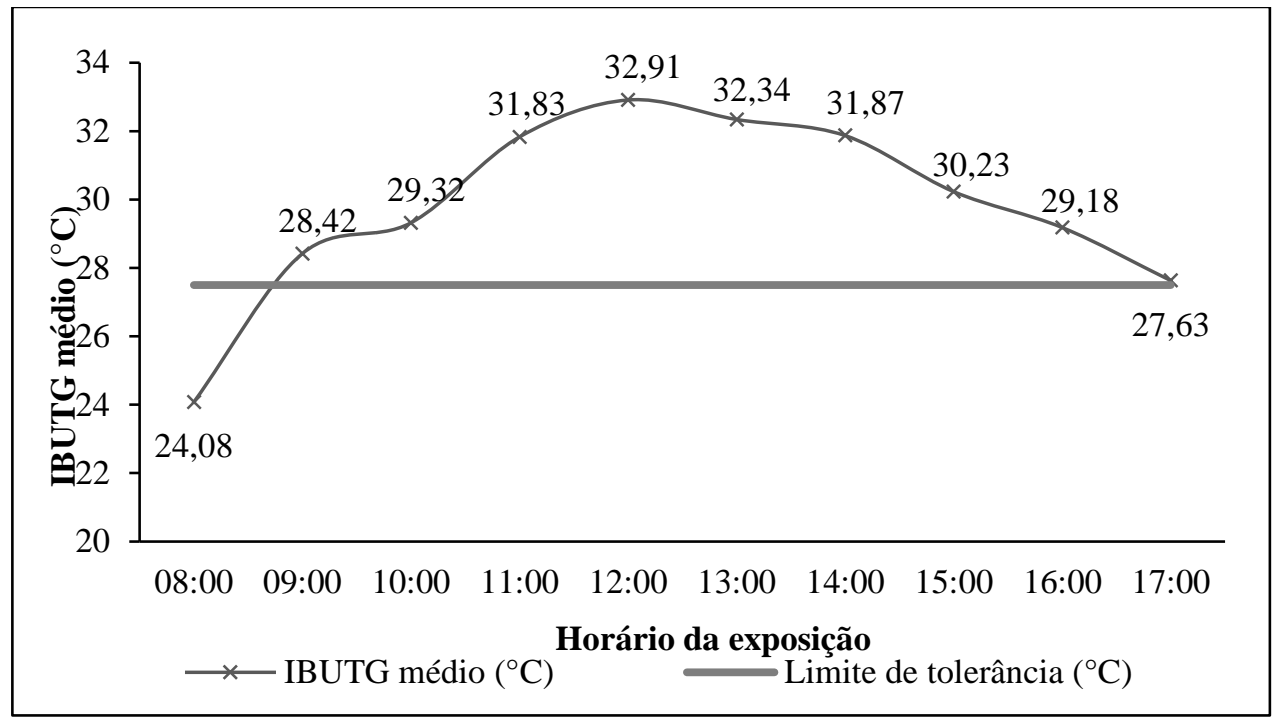

Fonte: Autoria própria (2016).

Pelo exposto, observa-se que as atividades realizadas pelos operadores de rampa são realizadas em condições térmicas inadequadas. A situação é agravada pelo fato de que além da agilidade necessária aliada às intensas solicitações biomecânicas durante o processo de carregamento e descarregamento das bagagens e mercadorias das aeronaves, a característica termo física da pavimentação asfáltica do aeródromo associada à temperatura interna do compartimento da aeronave provoca carga adicional de calor por convecção e radiação, potencializando, assim, a sensação de sobrecarga térmica.

Camargo e Furlan (2011) afirmam que tais condições térmicas afetam o sistema de produção e troca de calor do corpo com o ambiente e interfere no sistema termorregulador do corpo, produzindo fadiga, extenuação física e nervosa, diminuição do rendimento, aumento nos erros e riscos de acidentes no trabalho, além de expor o organismo a diversas doenças (COUTO, 1987; IIDA, 2005). Por este motivo, acredita-se durante os picos de sobrecarga térmica aumenta-se a probabilidade de negligência com o tratamento dispensado às bagagens e mercadorias por parte dos operadores.

Em relação ao ruído ocupacional, foi observado que os agentes de bagagens estavam expostos a níveis de ruído na ordem de $89,52 \mathrm{~dB}(\mathrm{~A})$ e os operadores de rampa de 93,63 dB (A). A Associação Brasileira de Normas Técnicas (ABNT), por meio da NBR 10152, estabelece que o nível de ruído aceitável para efeito de conforto deve ser de até $65 \mathrm{~dB}(\mathrm{~A})$, enquanto a NR 15 estabelece que para efeito de insalubridade, o tempo de exposição diária permissível de 6 horas de trabalho não deve exceder o limite de tolerância de $87 \mathrm{~dB}$. Segundo Gugliermetti et al. (2010), a exposição ocupacional a níveis elevados de ruído causa traumas auditivos, alterações fisiológicas extra auditivas e a Perda Auditiva Induzida pelo Ruído (PAIR). 
A Figura 6 demonstra o comportamento dos níveis de ruído médio que os operadores de rampa estavam expostos durante as operações próximas às aeronaves, na qual é possível notar a formação de quatro picos. O primeiro pico ocorreu às $08 \mathrm{~h} 45 \mathrm{~min}$, quando o nível de ruído atingiu $117,24 \mathrm{~dB}(\mathrm{~A})$, o segundo às $09 \mathrm{~h} 57 \mathrm{~min}$, quando atingiu $125,67 \mathrm{~dB}(\mathrm{~A})$, o terceiro às $13 \mathrm{~h} 59 \mathrm{~min}$, quando atingiu $118,87 \mathrm{~dB}(\mathrm{~A})$ e o quarto e último pico às $16 \mathrm{~h} 48 \mathrm{~min}$, quando atingiu $119,38 \mathrm{~dB}(\mathrm{~A})$. Esses picos foram formados devido aos pousos e decolagens de outras aeronaves no aeródromo. Os níveis de ruído compreendido entre 80 e 100 dB (A) foram ocasionados pelas atividades concomitantes de preparação da aeronave, denominada turnaround.

Figura 6 - Comportamento dos níveis de ruído médio durante a jornada de trabalho

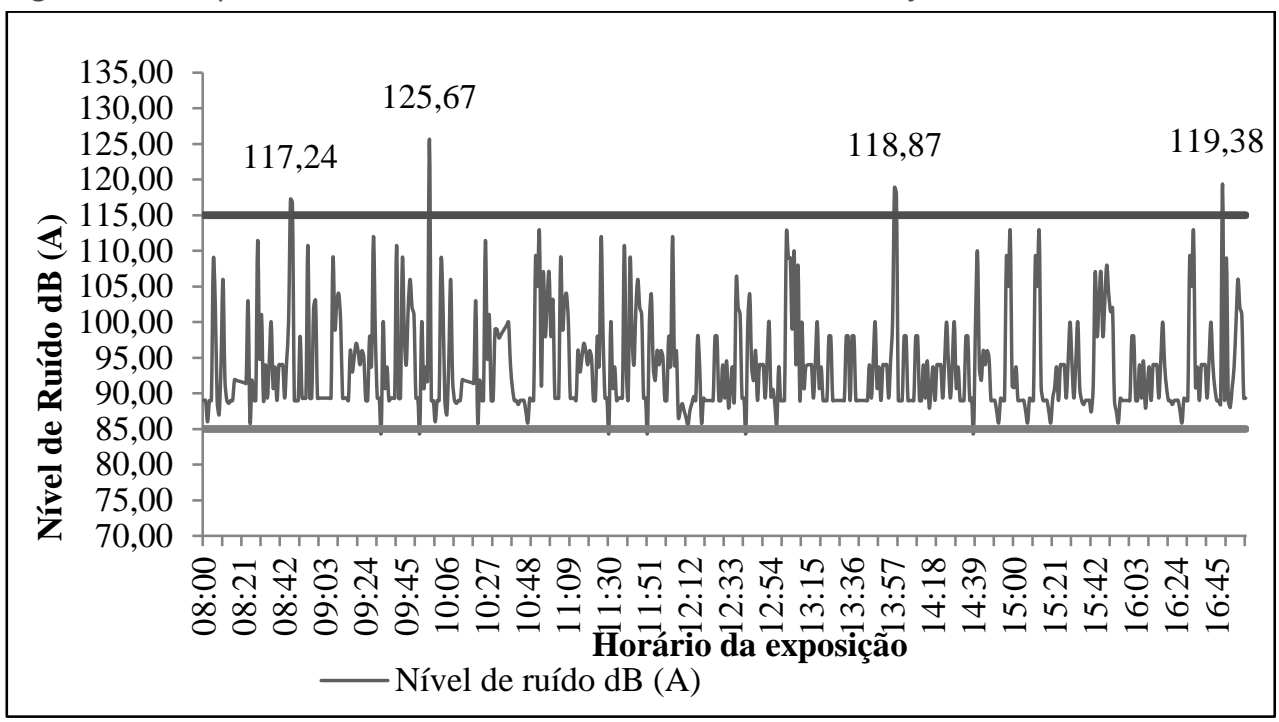

Fonte: Autoria própria (2016)

No que tange à iluminação dos postos de trabalho, foi possível perceber que pelas atividades ocorrerem em ambiente a céu aberto, a iluminação, consequentemente, se dá por iluminação natural. Assim, observou-se que os agentes de bagagem estavam expostos a níveis de iluminância média de 641,63 Ix e os operadores de rampa de 938,78 Ix. Esses níveis de iluminância encontram-se acima das especificações da NBR 5413, que recomenda para o tipo de atividade desenvolvida por esses trabalhadores uma iluminância de 100 a 300 Ix. Analisando especificamente o caso dos operadores de rampa, ao considerar a necessidade de níveis mais baixos de iluminação no posto de trabalho, acredita-se que o excesso de luminosidade ocasionada pela radiação solar e potencializado pelo tipo de tinta utilizado na fuselagem da aeronave pode causar fadiga visual, esgotamento nervoso, incidência de erros e ocorrência de acidentes, conforme salientado por lida (2005).

\section{PROPOSIÇÃO DE SOLUÇÕES ERGONÔMICAS}

Diante dos fatores de riscos de doenças ocupacionais identificados ao longo deste estudo, algumas recomendações ergonômicas foram apresentadas aos representantes da empresa responsável pelos serviços de assistência em terra, das companhias aéreas e da INFRAERO. 
Em relação à sobrecarga física de trabalho dos operadores de rampa, foi evidenciada a disponibilidade de uma gama de equipamentos no mercado que fornecem assistência mecânica para o carregamento e descarregamento de bagagens e mercadorias em aeronaves, conforme ilustrado na Figura 7. De acordo com Riley (2009), esses equipamentos além de evitar o trabalho manual intenso, reduzem o risco de avaria das bagagens e mercadorias, seja pela manipulação inadequada, seja pelas condições meteorológicas adversas.

Figura 7 - Equipamentos para automatização do processamento de bagagem e mercadoria em aeroportos

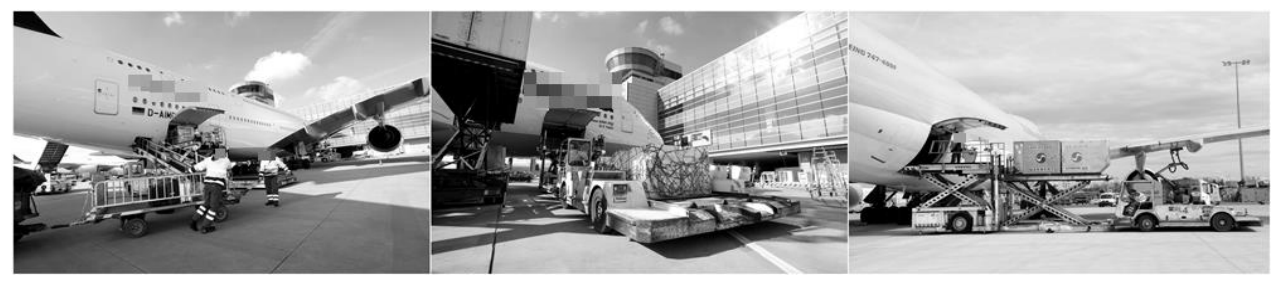

Fonte: www.fraport.com

No caso dos agentes de bagagem, foi recomendada a utilização de dispositivos de elevação no setor de triagem das bagagens e mercadorias. Esses dispositivos têm sido amplamente utilizados na maioria dos aeroportos internacionais, devido sua flexibilidade e capacidade de manuseio de grande variedade de bagagem ou mercadoria no que tange a dimensão, formato e peso. Seu princípio é o de prender os volumes a partir de qualquer lado, elevá-los e depositá-los no local préestabelecido de forma segura, conforme ilustrado na Figura 8.

Figura 8 - Equipamento de elevação de bagagem e mercadoria

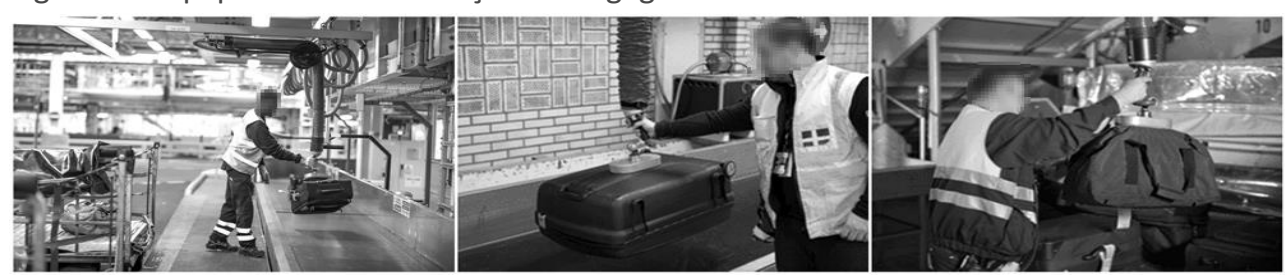

Fonte: www.vaculex.com.

Um estudo conduzido pelo NIOSH (2015) investigou a eficiência dos dispositivos de elevação durante o manuseio de bagagens em um aeroporto internacional. Os resultados demonstraram que comparado ao transporte manual, o dispositivo de elevação reduziu as forças de tração e compressão em aproximadamente $90 \%$, além de proporcionar a utilização de posturas neutras, sem ângulos de flexão de tronco. Dessa forma, concluíram que a produtividade foi potencialmente aumentada enquanto os riscos de desenvolvimento de lombalgias foram potencialmente reduzidos.

Ademais, frisou-se que, em curto prazo ou não havendo a possibilidade de utilização de mecanismos automatizados, deve-se adaptar o posto de trabalho, bem como o aparato instrumental necessário para a execução das atividades laborativas às medidas antropométricas da maioria dos trabalhadores. Para evitar o uso de biomecânica inadequada, orientou-se que ao manipular as bagagens e mercadorias os joelhos dos trabalhadores devem manter-se semi flexionados, a coluna ereta e a conservação do volume próximo ao eixo longitudinal do corpo, 
evitando, sobretudo, a flexão do tronco ou a rotação do corpo durante o processo. A eficácia dessas recomendações é comprovada em estudos como os de Waters (1993) e NIOSH (2015) que relacionam a diminuição da distância corpo-carga como fator redutor da sobrecarga na coluna vertebral.

Recomendou-se, também, que os tratoristas de reboque posicionem os carros de apoio perpendicularmente às esteiras rolantes para diminuir o ângulo de giro do tronco de $180^{\circ}$ para $90^{\circ}$. Do mesmo modo, posicionem os carros de apoio paralelamente aos compartimentos da aeronave. Além disso, foi solicitado que as companhias aéreas fornecessem etiquetas com a indicação do peso da bagagem e da mercadoria, sendo que as de maior peso devem ser transportadas por dois trabalhadores, conforme sugerido por Korkmaz et al. (2006) e Tapley e Riley (2005).

Em relação aos problemas ambientais identificados nos postos de trabalho, foi sugerida a utilização de protetor solar, observado o tipo e sensibilidade da pele dos trabalhadores, para reduzir os efeitos nocivos da radiação solar sob a pele. Salientou-se que as vestimentas devem ser confeccionadas, preferencialmente, em tecidos leves e com micro canais nos fios, pois conduzem a transpiração para o lado externo do tecido, fazendo com que seque rapidamente; além do uso de Equipamentos de Proteção Individual (EPI), como luvas, botas e boné com proteção lateral ampla para orelhas e pescoço. Este último foi sugerido devido ao fato de que não foi observada a utilização de proteção para a cabeça dos operadores de rampa durante a exposição aos raios solares.

Em relação à exposição ao ruído ocupacional, embora tenha sido observada a utilização de protetores auriculares do tipo concha, que segundo especificações técnicas do produto possui capacidade de atenuação de 17 a $27 \mathrm{~dB}(\mathrm{~A})$, foi recomendada a utilização de alternativas fisiológicas como a redução do tempo de exposição a partir da realização de pausas e rodízio de função, mesmo que a atenuação dos protetores auriculares seja suficientemente capaz de gerar uma situação segura, sem grandes danos à saúde. Do mesmo modo, para reduzir os efeitos da luminosidade excessiva, além da redução no tempo de exposição, foi recomendada a adoção de proteção visual por meio de óculos foto protetor ou equipamentos equivalentes.

\section{CONCLUSÕES}

Este estudo teve como objetivo avaliar as condições reais de trabalho dos agentes de bagagem e operadores de rampa de um aeroporto brasileiro para identificar os fatores de riscos associados às atividades desenvolvidas por esses trabalhadores e propor soluções ergonômicas passíveis de serem realizadas pela empresa.

Neste estudo, ficou evidente que todas as atividades desenvolvidas pelos agentes de bagagem e operadores de rampa demandam força muscular intensa. A aplicação da ELR permitiu que a hipótese previamente considerada de que o peso das bagagens e mercadorias não estava dentro dos limites ideais de fosse confirmada, pois demonstrou que o peso máximo a ser levantado pelos agentes de bagagem deve de $9,20 \mathrm{~kg}$ e para os operadores de rampa de 7,75 kg. A análise biomecânica reforça estes achados, na medida em que indicou o uso de esforço demasiado para rotação, flexão e extensão de tronco, associadas ao levantamento 
de bagagem e mercadorias; tendo como consequência a compressão média ao nível da coluna lombar dos agentes de bagagem na ordem de $3394 \mathrm{~N}$ e dos operadores de rampa de 3395,31 N.

No que se refere às condições ambientais de trabalho, foi possível perceber que algumas variáveis ambientais estavam fora dos limites de tolerância estabelecidos pela legislação brasileira, em especial, a temperatura, iluminação e ruído. Em relação ao conforto térmico, a temperatura média de ambos os postos de trabalho estava pouco mais que $11 \%$ acima do limite recomendado pela NR 17. Em corroboração, o IBUTG médio calculado para os trabalhadores estava fora do limite de tolerância estipulado pela NR 15. Especificamente, para os agentes de bagagem o IBUTG médio estava $2,65 \%$ acima do limite de exposição e para os operadores de rampa estava $8,29 \%$.

No que tange ao ruído ocupacional, observou-se que os trabalhadores estavam expostos a níveis elevados de pressão sonora. 0 ruído médio no posto de trabalho dos agentes de bagagem encontrava-se 2,90\% acima do limite estabelecido pela NR 15, enquanto no posto de trabalho dos operadores de rampa estava $7,62 \%$. Constatou-se, ainda, que a iluminação nos postos de trabalho dos agentes de bagagem $(113,87 \%)$ e operadores de rampa $(212,92 \%)$ estava acima dos limites estipulados pela na NBR 5413.

Não obstante as limitações deste estudo, algumas contribuições foram alcançadas, dentre elas, duas não podem ficar sem menção. A primeira pelo preenchimento da lacuna existente na literatura com relação a estudos das condições de trabalho com agentes de bagagem e operadores de rampa nos aeroportos brasileiros. A segunda, por identificar os principais fatores de riscos de doenças ocupacionais inerentes a essa profissão e, sobretudo, evidenciar a necessidade de uma fiscalização mais rígida por parte dos órgãos competentes.

De forma geral, espera-se que os resultados deste estudo sensibilizem os gestores do aeroporto de forma que as proposições ergonômicas sejam realizadas, para que a integridade física desses profissionais seja preservada, e assim, propicie o desempenho eficiente no exercício de suas atribuições. 


\title{
Evaluation of the Working Conditions of Baggage Agents and Ramp Operators of a Brazilian Airport
}

\begin{abstract}
The aim of this study was to evaluate the working conditions of baggage agents and ramp operators of a Brazilian airport to identify the risk factors associated with the activities developed by these workers and to propose ergonomic solutions that can be carried out by the company. For this purpose, the following measurements were performed: of the anthropometry of workers; of the instrumental apparatus used in work activity; of the biomechanics used during the execution of the tasks; and of the environmental variables of the workplaces. The assessment of biomechanical conditions of work was carried out using the 3D Static Strength Prediction Program (3DSSPP) and the Revised Lifting Equation (RLE) of the National Institute for Occupational Safety and Health (NIOSH). The evaluation of the environmental conditions of work was carried out by comparing the limits of tolerance established by Brazilian legislation and the levels measured in the workplace. In relation to biomechanical conditions of work, it was evident that the manual handling of baggage and goods weighing above the recommended caused potentially harmful compressions to the lumbar spine, mainly of the ramp operators. As regards to environmental conditions of work, the results showed that some environmental variables were outside the limits of tolerance, especially the temperature, lighting and noise. Overall, it is expected that the risk factors identified in this study will sensitize the managers so that the ergonomic propositions should be carried out systematically.
\end{abstract}

KEYWORDS: Work conditions. Baggage agent. Ramp operator. Airport. 


\section{REFERÊNCIAS}

ASSOCIAÇÃO BRASILEIRA DE NORMAS TÉCNICAS - ABNT - NBR 5413. Rio de Janeiro, 1991.

ASSOCIAÇÃO BRASILEIRA DE NORMAS TÉCNICAS (ABNT). NBR 10152: Níveis de ruído para conforto acústico. Rio de Janeiro, 2000.

AGÊNCIA NACIONAL DE AVIAÇÃO CIVIL (ANAC). Anuário do Transporte Aéreo. Rio de janeiro, 2016. Disponível em: http://www.anac.gov.br/. Acesso em: out/2016.

BRASIL, MTE. Normas regulamentadoras de segurança e saúde no trabalho: Atividade e operações insalubres (NR-15), 2004. Disponível em: <http://trabalho.gov.br/seguranca-e-saude-no-trabalho/normatizacao/normasregulamentadoras>. Acesso em: out/2016.

BRASIL, MTE. Normas regulamentadoras de segurança e saúde no trabalho: Ergonomia (NR-17). 2009. Disponível em: <http://trabalho.gov.br/seguranca-esaude-no-trabalho/normatizacao/normas-regulamentadoras $>$. Acesso em: out/2016.

BRASIL. Norma Técnica sobre Lesões por Esforços Repetitivos-LER ou Distúrbios Osteomusculares Relacionados ao Trabalho-DORT. Diário Oficial da União, 2003.

BRASIL. Fundacentro. Norma de Higiene Ocupacional NHO 01: Procedimento Técnico - Avaliação da Exposição Ocupacional ao Ruído, São Paulo, 1999.

BRASIL. Fundacentro. Norma de Higiene Ocupacional NHO 06: Procedimento Técnico - Avaliação da Exposição Ocupacional ao Calor, São Paulo, 2002.

BYRNS, G.E.; BIERMA, T.J.; AGNEW, J.; CURBOW, B. A new direction in low back pain research. American Industrial Hygiene Association Journal, v 63, n. 1, p. 5561, 2002.

CAMARGO, M. G.; FURLAN, M. M. D. P. Resposta fisiológica do corpo às temperaturas elevadas: exercício, extremos de temperatura. Revista Saúde e Pesquisa, v. 4, n. 2, p. 278-288. 2011.

CONFEDERAÇÃO NACIONAL DO TRANSPORTE. 2015. Transporte e economia: transporte aéreo de passageiros. Brasília, 2015. Disponível em: http://www.cnt.org.br/. Acesso em: out/2016. 
COUTO, H. A. Ergonomia aplicada ao trabalho: manual técnico da máquina humana. Vol. 2. Belo Horizonte: ERGO Editora, 1996.

GUGLIERMETTI, F.; BISEGNA, F.; VIOLANTE, A. C.; AURELI, C. Noise exposure of the ramp's operators in airport apron. Proceedings book of 20th International Congress on Acoustics, ICA, 2010. Disponível em : <www.acoustics.asn.au>. Acesso em: out/2016.

IIDA, I. Ergonomia: Projeto e Produção. 2ª ed. São Paulo: Blucher, 2005.

KORKMAZ, S.V., HOYLE, J.A., KNAPIK G.G., SPLITTSTOESSER, R.E., YANG, Y., TRIPPANY, D.R., LAHOTI, P., SOMMERICH, C.M., LAVENDER, S.A., MARRAS, W.S. Baggage handling in an airplane cargo hold: An ergonomic intervention study. International Journal of Industrial Ergonomics, v. 36, 2006, p. 301-312.

MERINO, E. A. D. Efeitos agudos e crônicos causados pelo manuseio e movimentação de cargas no trabalhador. 1996. Dissertação (Mestrado) Universidade Federal de Santa Catarina, Florianópolis, 1996.

NATIONAL INSTITUTE FOR OCCUPATIONAL SAFETY AND HEALTH (NIOSH). Reducing musculoskeletal disorders among airport baggage screeners and handlers. Department of Health and Human Services (NIOSH), Public health Service, Cincinnati, OH, 2015.

OXLEY, L.; RILEY, D.; TAPLEY, S. (2009). Musculoskeletal ill-health risks for airport baggage handlers - Report on stakeholders project at East Midlands Airport. Health and Safety Executive. 2009, p. 1-106.

RILEY, D. (2009). Reducing the risks associated with the manual handling of air passenger baggage for narrow bodied aircraft - Literature review update. Health and Safety Executive. 2009, p. 1-34.

TAFAZZOL, A; AREF, S.; MARDANI, M.; HADDAD, O.; MOHAMAD, P. Epidemiological and Biomechanical Evaluation of AirlineBaggage Handling, International Journal of Occupational Safety and Ergonomics, v. 22, n.2, p. 218227, dec. 2015.

TAPLEY, S.; RILEY, D. Baggage handling in narrow-bodied aircraft: Identification and assessment of musculoskeletal injury risk factors. East \& South East Specialist Group, v. 1, p.1-26. 2005.

TEIXEIRA, E.R. Sistematização de procedimentos necessários à aplicação da ELN: estudo descritivo da relação entre o IL da equação revisada do NIOSH e a 
incidência de lombalgia numa amostra de trabalhadores. 2004. 224 f.

Dissertação (Mestrado em Engenharia Mecânica) - Setor de Tecnologia, Universidade Federal do Paraná, Curitiba.

WATERS, T. R. et al. (1993). Revised NIOSH equation for the design and evaluation of manual lifting task. Ergonomics. London, v. 36, n. 7, p. 749-776.

YOOPAT, P.; TOICHAROEN, P.; GLINSUKON, T.; VANWONTERGHEM, K.;

LOUHEVAARA, V. Ergonomics in practice: physical workload and heat stress in Thailand. International Journal of Occupational Safety and Ergonomics, v. 8, $\mathrm{n}^{\circ}$ 1, p.83-93. 2002.

ZIMMERMANN, N.; OLIVEIRA, A. V. M. Liberalização econômica e universalização do acesso no transporte aéreo: É possível conciliar livre mercado com metas sociais e ainda evitar gargalos de infraestrutura. Journal of Transport Literature, v. $6, n^{\circ} 4$, p. $82-100,2012$.

Recebido: 15 nov. 2016

Aprovado: 06 fev. 2017

DOI: $10.3895 /$ gi.v13n1.5021

Como citar:

SANTOS, J. W.; MONTEIRO, L. F. Avaliação das condições de trabalho de agentes de bagagem e operadores de rampa de um Aeroporto Brasileiro. R. Gest. Industr., Ponta Grossa, v. 13, n. 1, p. 38-56, jan./mar. 2017. Disponível em: <https://periodicos.utfpr.edu.br/rgi>. Acesso em: XXX.

Correspondência:

José Wendel dos Santos

Rua Verde Rosa, 94, Lamarão, Aracaju, SE, Brasil.

Direito autoral: Este artigo está licenciado sob os termos da Licença Creative Commons-Atribuição 4.0 Internacional. 